\title{
Agrobacterium tumefaciens Mediated Transformation of Symbiodinium spp.
}

\author{
Buntora Pasaribu ${ }^{1, *}\left(\mathbb{D}\right.$, Pei-Luen Jiang ${ }^{2, *}$ \\ ${ }^{1}$ Rutgers University, Department of Plant biology, New Brunswick, USA \\ ${ }^{2}$ National Formosa University, Department of Biotechnology, Taiwan
}

\begin{abstract}
How to cite
Pasaribu, B., Jiang, P.-L. (2021). Agrobacterium tumefaciens Mediated Transformation of Symbiodinium spp. Turkish Journal of Fisheries and Aquatic Sciences, 21, 291-298. http://doi.org/10.4194/1303-2712-v21_6_04
\end{abstract}

\section{Article History}

Received 04 January 2021

Accepted 18 March 2021

First Online 22 March 2021

\section{Corresponding Author}

Tel.: +88656315491

E-mail: buntora86@gmail.com villy@nfu.edu.tw

\section{Keywords}

Agrobacterium tumefaciens

Symbiodinium

Transformation

\begin{abstract}
Symbiodinium spp conducts symbiosis mutualism within a wide phyletic range of marine invertebrate hosts including corals and anemones. The present study investigates the transformation of foreign genes into the free living cultured Symbiodinium spp by co-cultured Symbiodinium cells with $A$. tumefaciens. Ti-plasmidbased binary vector harboring the GUS and GFP genes were transformed into Symbiodinium cells by co-cultivation. GUS histochemical assay was monitored in Symbiodinium cells under light microscopy. Putative GFP in transformed Symbiodinium cells was detected by immunoassaying with antibodies against GFP protein. These results suggest that $A$. tumefaciens could provide efficient tools for gene transformation of Symbiodinium cells.
\end{abstract}

\section{Introduction}

Symbiodinium is a photosynthetic dinoflagellate that conducts mutual relationship within marine organisms including coral, clams and sea anemone (Davy et al., 2012; Pasaribu et al., 2015). As the role contributor, the presence of Symbiodinium maintains the stability of the host to survive. The host provides the organic nutrients for Symbiodinium and in exchange Symbiodinium translocates the photosynthesis product to the host (Muscatine, 1990). The interactive machinery of translocation could lead the genetic regulation and expression during symbiotic partnership. Several molecular and cellular studies have reported new insights to the genetic regulation of Symbiodinum have been reported recently (Jiang et al., 2014; Peng et al., 2011, Mayfield et al., 2013). However, there are limited studies describing the genetic transformation of Symbiodinium (Lohuis \& Miller, 1998). The development of genetic transformation technique could allow the exploitation of functional genetics in Symbiodinium.

In over a decade, the studies of gene transformation methods have been significantly developed in plants and algae (Wang et al., 2018; Mahto et al., 2018; Anila et al., 2011; Rathod et al., 2013). Several methods have been used for genetic transformation in algae including electroporation (Munoz et al., 2018), bombardment (Sharma et al., 2018), and glass beads (Ortiz et al., 2015). The unstable and low frequency transformation of these existing systems necessitate the development of alternative tools for gene transfer. Use of Agrobacterium tumefaciens ( $A$. tumefaciens) results in efficient and stable transformation in plant cells (Wang et al., 2018; 
Mahto et al., 2018). The presence of T-DNA as a part of Ti-plasmid in Agrobacterium tumefaciens enables integration at the target nuclear target chromosome (Bundock et al., 1995). It has been reported that the Agrobacterium mediated transformation was successfully achieved in microalgae such as Chlamydomonas reinhardtii (Kumar et al., 2004), Chlorella (Cha et al., 2012), Haematococcus (Kathiresan et al., 2009), and Schizochytrium (Cheng et al., 2012).

In this study, we developed an Agrobacterium mediated transformation system in Symbiodinium. Transformation attempted in Symbiodinium cells has been observed by treatment with biolistic, electroporation, glass bead, and polyethylene glycol of which the transformed cells were not capable of cell division (Ortiz-Matamoros et al., 2015a). The transformation of free living Symbiodinium cells with plant pathogen Agrobacterium was resulted the failed of transformed cell to reproduce under herbicide selection (Ortiz-Matamoros et al., 2015b). However, transformation of free living Symbiodinium spp by combining electroporation and agrobacterium have never been understood. Studies the free living Symbiodinium spp transformation through these methods will be able to carry out the simple method to explore the possible genetic tools for Symbiodinium spp. We generated the transformation of $\beta$-glucuronidase (GUS) and green fluorescence protein (GFP) genes were transformed into Symbiodinium cells by Agrobacterium tumefaciens mediated transformation and stable transformation of the exogenous gene in the transgenic Symbiodinium was assessed using molecular and immunoblot assays. Transformed Symbiodinium presented the blue labelling (GUS) and green fluorescence protein (GFP) signal intracellularly in Symbiodinium cells. This result could facilitate an alternative system for efficient and in elucidating the stable transformation in Symbiodinium.

\section{Material and Methods}

\section{Symbiodinium Culture}

Symbiodinium spp. (clade B) maintained in the $\mathrm{f} / 2$ medium in filtered seawater (FSW) at room temperature under a photo-synthetically active radiation (PAR) of 40 mmol m_2 s_1 in a 12-h light/12-h dark (12L/12D) cycle.

\section{Co-Cultivation of Symbidinium spp}

Agrobacterium strains harboring plasmids 35s:GUS and ubi:GFP were cultivated in $5 \mathrm{ml}$ of LB medium. The strains were supplemented with proper selective antibiotic and incubated at 28 for $48 \mathrm{~h}$ with shaking. Strains were collected by centrifugation at $5000 \times \mathrm{g}$ for 15 mins to an OD600 of 0.5. Then, Symbiodinium cells were submerged in agrobacterium suspension and an electroporator (BTX, San Diego) to assure the gene introduced into Symbiodinium cells was used.
Symbiodinium cells were cocultured with Agrobacterium strains after Acetosyringone (AS) induction for two days. Afterward, the Symbiodinium cells were transferred to $F / 2$ selection medium. The survival cells were cultured in the $f / 2$ medium for two weeks. All steps of transformation were carried out at $25^{\circ} \mathrm{C}$ under the light of $40 \mathrm{mmol} \mathrm{m}^{-2} \mathrm{~s}^{-1}$ in a 12-h light/12h dark (12L/12D) cycle.

\section{GUS Expression Essay}

Histochemical GUS staining was conducted as described by Ho et al. (2000). Symbiodinium wild type and transformed cells were cultured in $100 \mathrm{ml} \mathrm{ASW}$ with F/2 medium. Symbiodinium cells were collected by centrifugation at $12000 \times \mathrm{g}$ for $5 \mathrm{~min}$. The pellets were suspended in Histochemical buffer containing $1 \mathrm{~mm} 5$ bromo-4-chloro-3-indolyl b-D-glucuronide (X-gluc) and then incubated at $37^{\circ} \mathrm{C}$ in darkness for $12 \mathrm{~h}$. After incabtion, the Symbiodinium cells were suspended in $70 \%$ ethanol and rinsed with deionized water.

\section{DNA Extraction and PCR Analysis}

Total genomic DNA of Symbiodinium cells were extracted from wild type Symbiodinium as nontransformed control and transformed Symbiodnium cells using Plant genomic DNA extraction. The total genomic DNA from wild type and transformed Symbiodinium cells were detected for PCR analysis and GUS-specific primer were used. Primer used for GUS gene was GUS-F: 5'ATCAGCGCGAAGTCTTTATACC3' and GUS-R: 5'CAGTTGCAACCACCTGTTGA3'. PCR products were separated on a $1 \%$ agarose gel and observed by using UV machine.

\section{Fluorescent Microscopy}

Symbiodinium cells wild type and transformed were cultured for a week in F/2 medium. Symbiodinium cells were collected by centrifugation at $12000 \times \mathrm{g}$ for 5 min. The pellets were washed three times using $d_{d d} \mathrm{H}_{2} \mathrm{O}$ to remove any micelles from Symbiodinium cells. Symbiodinium cells wild type and transformed were visualized by Axioskop 2 Plus microscope (Zeiss, Germany) equipped with a charge-coupled device (CCD) camera (Coolsnap-Prock, Photometrics Ltd., USA).

\section{SDS-PAGE and Western Blotting}

Total proteins in Symbiodnium sp wild type and transformants were extracted with an equal volume of $2 x$ sample buffer according to the suggestions in the BioRad (Bio-rad, USA) Trans-Blot instruction manual and resolved by SDS-PAGE using $12 \%(\mathrm{w} / \mathrm{v})$ polyacrylamide in the separating gel and $4.75 \%$ polyacrylamide in the stacking gel (Schägger 2006). After electrophoresis, the gel was stained with Coomassie Blue R-250 and then destained. For Western blotting, proteins were 
transferred from SDS-PAGE onto a nitrocellulose membrane in a Trans-Blot system (Bio-Rad, USA) according to the manufacturer's instructions. The membrane was subjected to immune-detection using a primary antibody against GFP (25 kDA) The membrane was washed and visualized by Super Signal West Pice, Chemiluminescent substrate kit (Thermo Fisher Scientific, Watham, MA)

\section{Results}

\section{Pre-Treatment of Symbiodinium Cells}

Several transformation techniques using Agrobacterium have been successfully reported for Chlamydomonas (Kumara et al., 2004). However, dinoflagellate is a unique organism that grows in both free living and symbiotic forms. Thus, we first isolated fresh Symbiodinium cells from Exaiptasia pulchella via percoll gradient and maintained the cells in culture for a few months (Pasaribu et al., 2015). Free living Symbiodinium cells were coccoid yellow brown in color and 5-6 mm in diameter. Generally, the free-living Symbiodinium are smaller than symbiotic Symbiodinium (Pasaribu et al., 2015). To produce sufficient biomass for transformation, Symbiodinium cells were cultured in F/2 medium and aerated. The cells were grown until reaching the log phase and then used for transformation (Figure 1).

\section{Symbiodinium sp Transformation}

Agrobacterium tumefaciens carrying one of two binary vectors was used in this study. We used the CaMV35S promoter to drive expression of the GUS reporter genes and the ubiquitin promoter to drive expression of the GFP reporter genes (Figure 2). CaMV35S and ubiquitin are two common promoters that have been successfully used in plant transformation systems. Additionally, the well-established electroporation method of transformation has been successfully applied to transform foreign genes in many eukaryotic species. Pre-treated Symbiodinium cells were co-incubated for 24 hours with A. tumefaciens carrying either GUS or GFP genes and transformed using electroporation. Then, the free-living transformed Symbiodinium cells were cultured in $F / 2$ medium for hygromycin selection. After 7 days in selection medium, hygromycin resistant transgenic Symbiodinium cells were observed. Cells were stained using X-Gluc solution and monitored for GUS protein expression under light microscopy. For GFP expression, green fluorescence signal was observed in the transgenic Symbiodinium cells under fluorescence microscopy.

\section{GUS Staining and GFP Detection}

To determine the successful integration of the GUS gene into the genome of Symbiodinium cells, genomic
Vector preparation :

(A) 35::GUS ; (B) Ubi::GFP

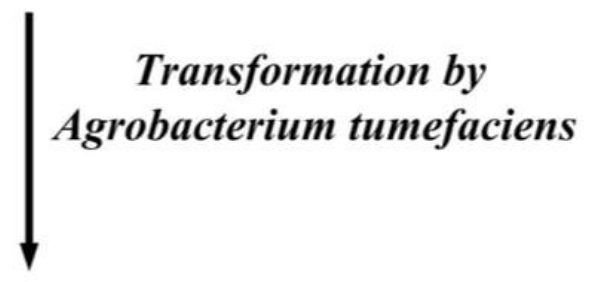

\section{Co-cultured with Symbiodinium cells}

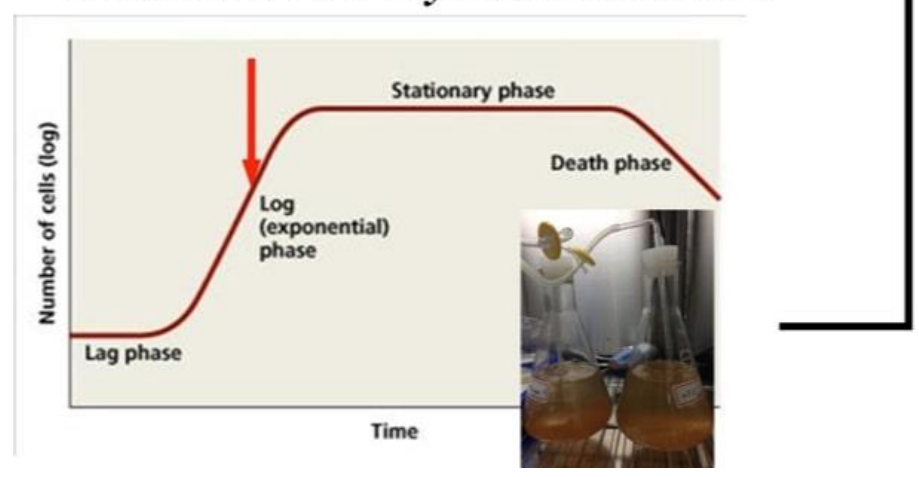

\section{T-DNA inserted into} Symbiodinium chromosome

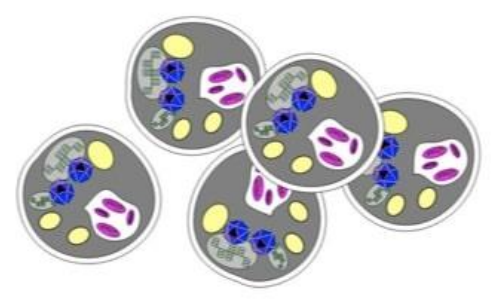

Transgenic Symbiodinium cells

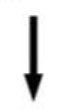
Detect by light microscopy Western blot gDNA

Figure 1. Overview of Agrobacterium-Symbidinium transformation. Vector transformed into Symbiodinium cells. T-DNA integrated into the Symbiodinium by co-culturing of Agrobcaterium and Symbiodinium. Inducible expression of reporter genes in transgenic Symbiodinium confirmed by microscopy and molecular approaches. 
DNA was isolated from transgenic and wild type of Symbiodinium sp. and the GUS gene was screened for using a PCR assay. DNA electrophoresis gels showed one band at $700 \mathrm{bp}$ representing the GUS gene that was detected in the transformants and agrobacterium sample (Figure 3). The GUS gene was clearly not detected in the wild type and used as negative control. This suggests that the transgenics line contained the GUS gene. To confirm whether the GUS gene was expressed in the Symbiodinium cells, we performed the GUS histochemical assay. GUS is commonly used as marker gene system for transgenic plants. With this approach, stained cells expressing the GUS gene would appear blue after a reaction with the substrate (X-gluc). Blue cells were observed under the microscope, thus confirming GUS gene expression in transgenic Symbiodinium sp. (Figure 4).
To examine green fluorescent protein (GFP) expression, the transgenic Symbiodinium cells were observed under the fluorescence microcope. Our result showed the green fluorescence signal observed in transgenic Symbiodinium sp but absent in wild type strains (Figure 5). We also confirmed the protein expression extracted from wild type and transgenic Symbiodinium cells. No band was observed in wild type Symbiodinium while one major protein band with a molecular weight of $27 \mathrm{kDA}$ was detected in in transgenic Symbiodinium when cross-recognized with antibodies against green fluorescent protein (GFP) (Figure 5). This result indicates the exogenous of green fluorescent protein (GFP) genes was successfully integrated in Symbiodinium cells. Furthermore, Symbiodinium sp. could be potentially engineered from two main types of isolated Symbiodinium cells such as free living and symbiotic in cnidarians cells.

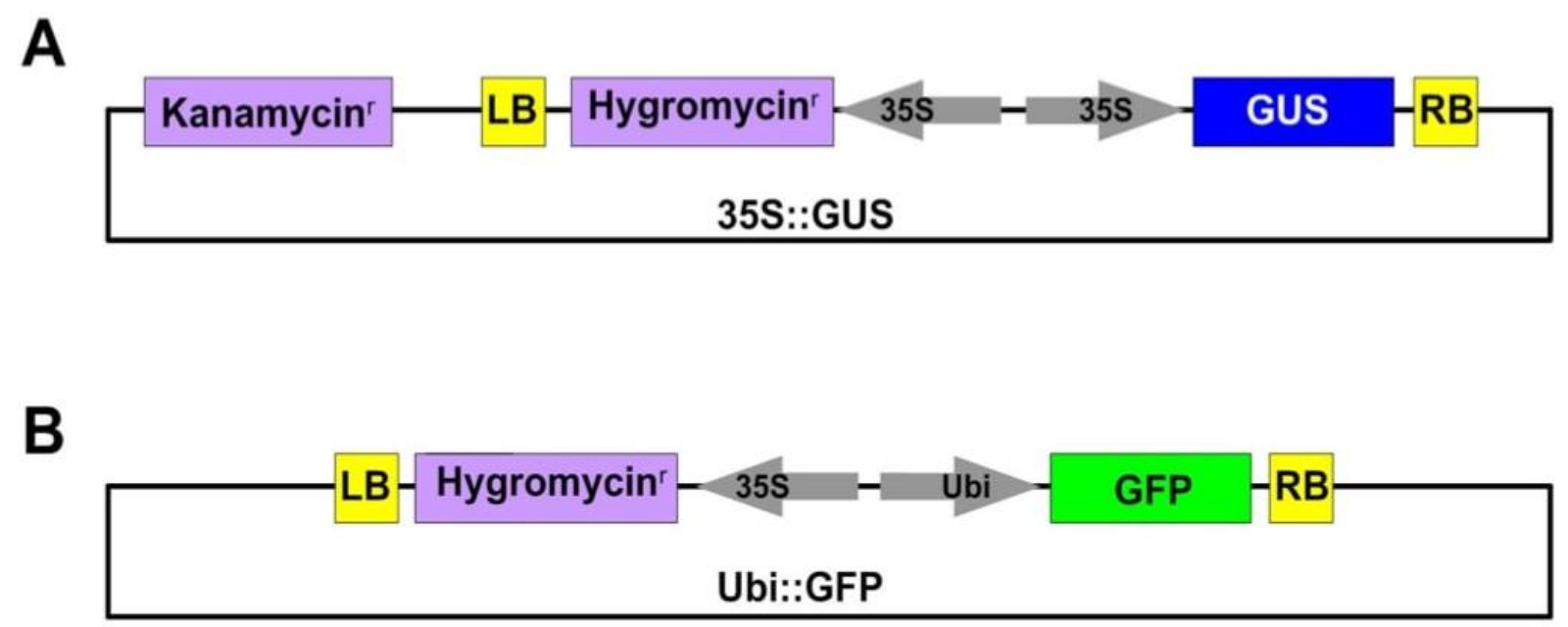

Figure 2. Schematic diagram of plasmids used for transformation in Symbiodinium sp. (A) CaMV35S promoter drives the reporter genes GUS (B) Ubiquitin promoter drives the reporter genes GFP.

A

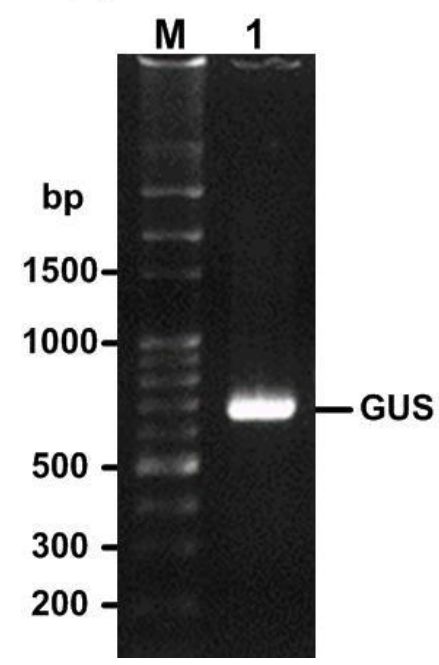

B

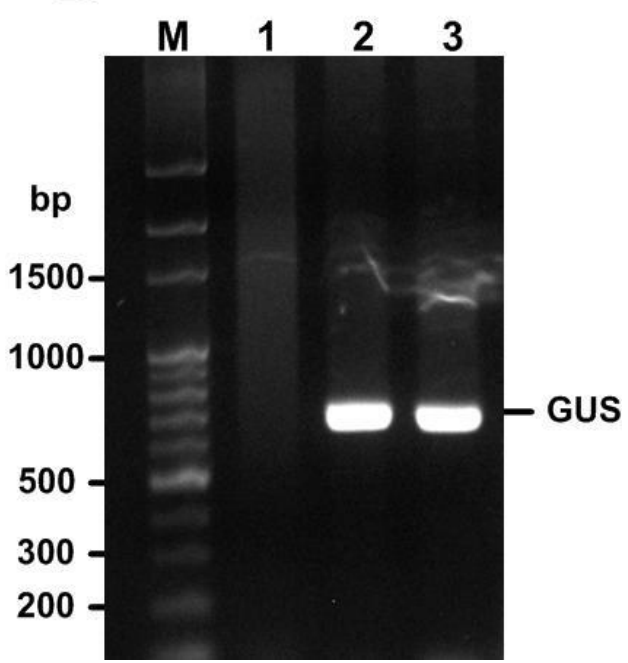

Figure 3. Agarose gel electrophoresis of GUS detection. (A) GUS confirmation for transformation plasmid of pCAMBIA to Symbiodinium. (B) PCR analysis using GUS gene detected in transgenic Symbiodinium (lane 2 and 3), no band detected in wild type Symbiodinium (lane 1). Positions of M.W. standards are indicated at left. 

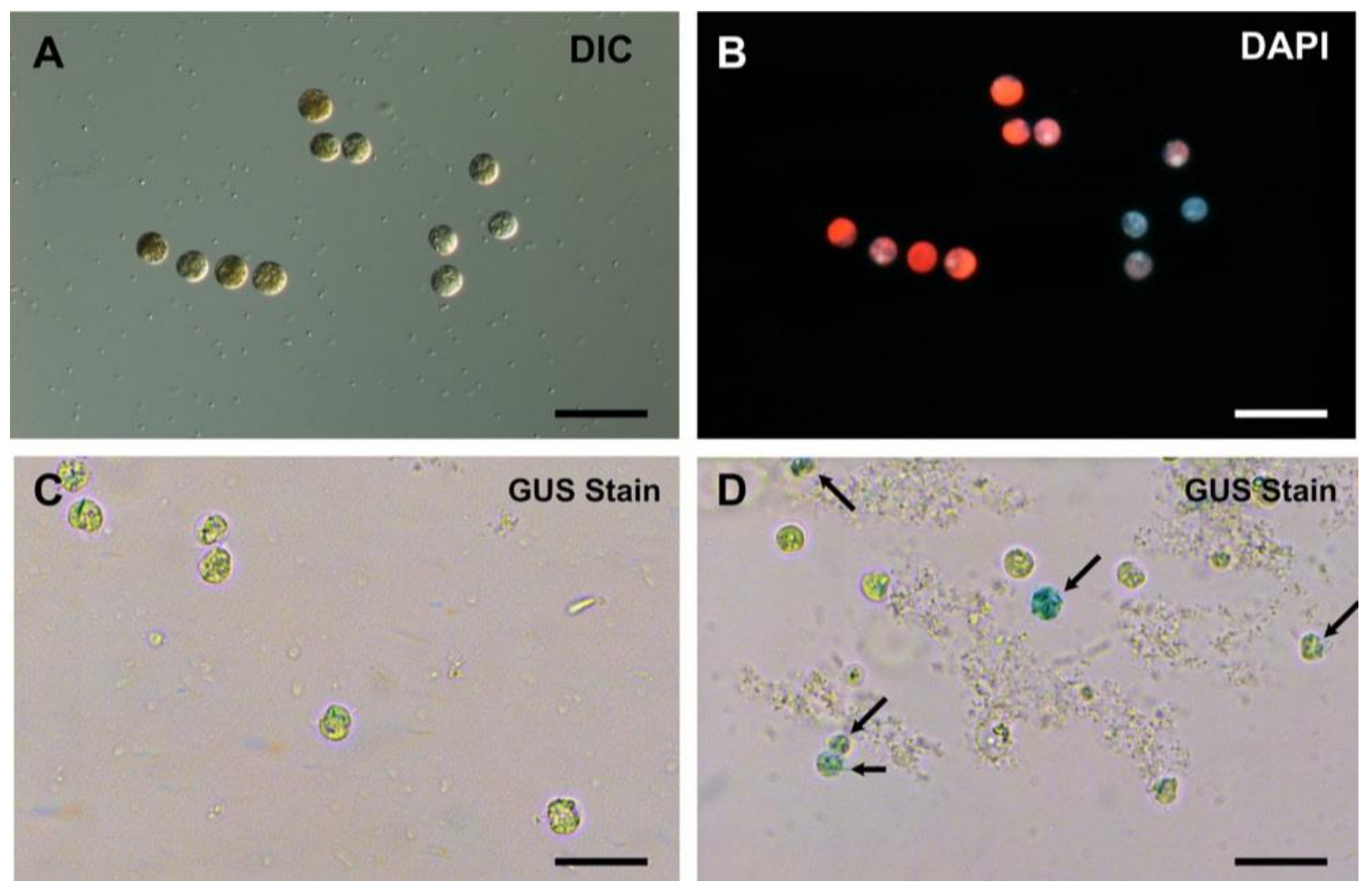

Figure 4. Microscopic observation of GUS staining in Symbiodinium cells. (A-B) Fresh isolated Symbidinium cells were brown in color. Red fluorescence represented the chlorophyll and blue color showed death cells of fresh isolated Symbiodinium. (C) Free living cultured Symbiodinium cells showed no staining at all. (D)Transgenic free living cultured Symbiodinium cells showing blue color due to activity of GUS. Positive staining indicated by the black-filled arrowheads. Scale bar, $10 \mu \mathrm{m}$.
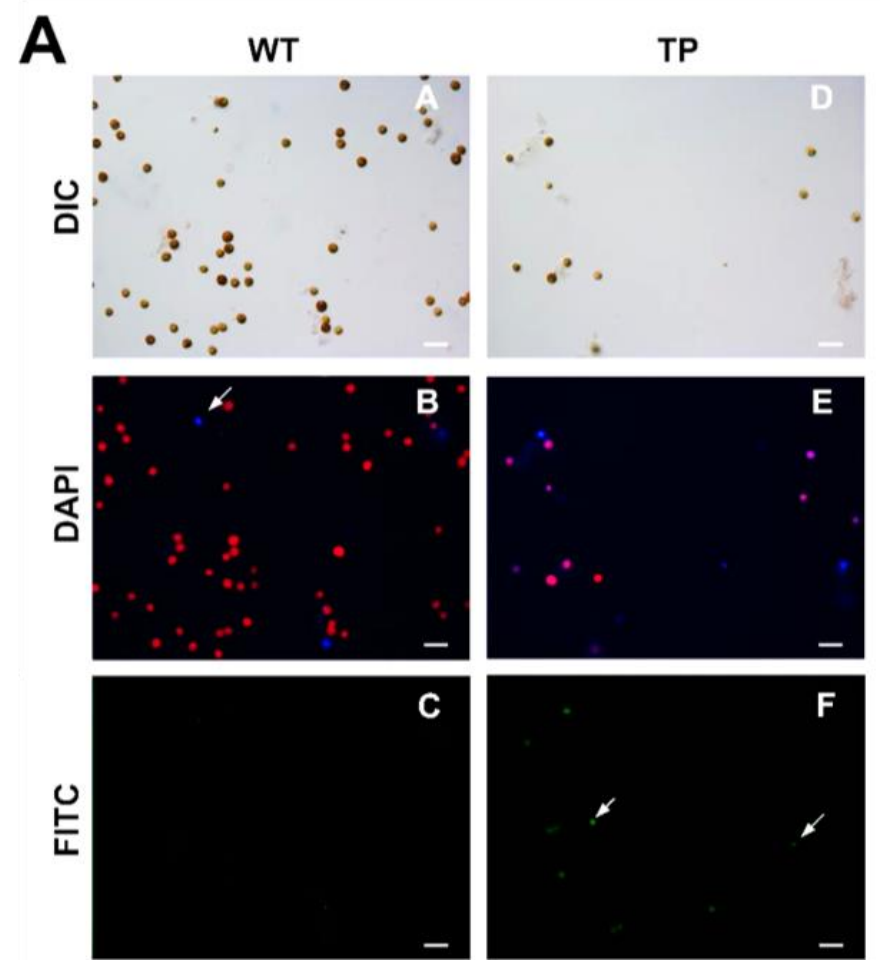

B

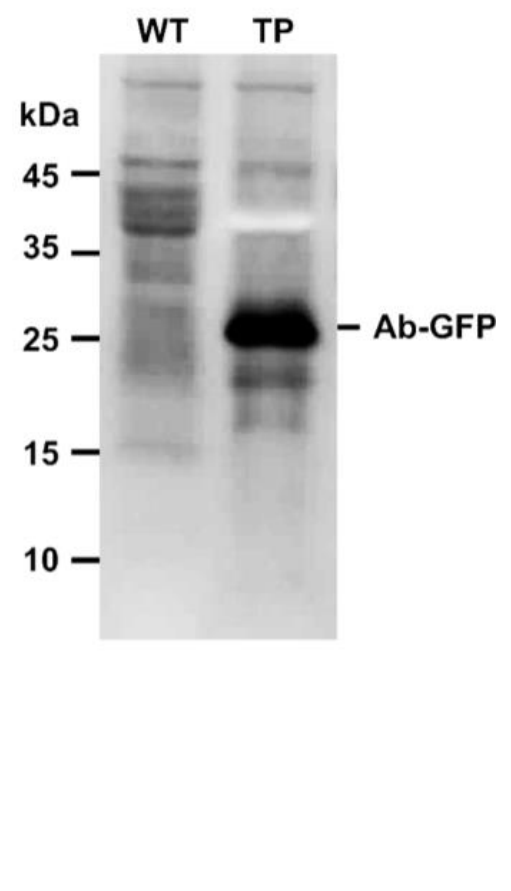

Figure 5. Microscopic and Western blot of Protein extracted from Symbiodinium cells. (A) Microscpic image of wild type (A,B,C) and transgenic Symbiodinium cells $(D, E, F)$. Red fluorescence indicated chlorophyll $(B, E)$ whereas the blue fluorescence represented death cells of Symbiodinium spp (B) indicated by the white-filled arrowheads. Green fluorescence (F) indicated by the white-filled arrowheads. Scale bar, $10 \mu \mathrm{m}$ (B) Protein total extracted from wild type and transgenic Symbiodinium sp were resolved in SDS-Page and subjected to immunodetection gfp $(27 \mathrm{kDa})$. The gfp detected by immunoassaying marked with black strip on the right of the protein band. 


\section{Discussion}

Agrobacterium is an efficient tool to transfer foreign genetic material into the plant cells (Newell, 2000). Agrobacterium contains a unique transfer component that enables Ti-plasmid integration into the plant nuclear genome (Gelvin, 2003). GUS ( $\beta$ glucuronidase) and GFP (green fluorescent protein) are commonly used reporter systems for visualizing gene expression in eukaryotic cells (Lorang et al., 2001). It has been reported that GFP and GUS reporters driven by $35 \mathrm{~S}$ promoter were successfully used for agrobacterium transformation of algae (Cheng et al., 2012; Lohuis \& miller, 1998). In the present study, two plasmids were used for assessing transformation of exogenous genes included reporter (GUS) driven by $35 \mathrm{~S}$ promoter and reporter (GFP) driven by $\mathrm{UBI}$ promoter. In fact, the critical point for obtaining efficient transformation in Symbiodinium depends on the environment and growth response in each species. We demonstrated the transformation is based on the growth phase, therefore, the cells proliferation and survival could be optimized in transformed Symbiodinium. Accordingly, establishment of an efficient transformation Agrobacterium-mediated transformation in algae required the appropriate selectable period of growth and media to enable the successful transformation (Kumar et al., 2004; Rathod et al., 2013).

Transformation contacts between A. tumifaciens and the host are considered to play a key role in achieving proper transformation efficiencies of T-DNA transfer. It is necessary to generate the simple and reliable procedure to infiltrate $A$. tumifaciens. Various techniques have been applied for introducing $A$. tumifaciens strains such as pollen mediated, injection, and microprojectile bombardment in plant cells (Xu et al., 2014; Liu \& Pijut, 2010; Manickavasagam et al., 2015). Considering Symbodinium cells size and morphology, Pasaribu et al. (2014) reported Symbiodinium cells could be disrupted by using beads. Therefore, we applied the electroporation method in Symbiodinium cells. It has been reported that electroporation method have been successfully applied to transform foreign genes in many eukaryotic species (Munoz et al., 2018). Electroporation is a simple method that enhances the access of A. tumifaciens to infiltrate the T-DNA transfer to cells the nuclear genome. The infiltration of Agrobacterium T-DNA is activated by inducer of vir region so called Acetosyringone (AS) at wounding site. Our results show GUS and GFP genes were expressed in Symbiodinium cells. We noted that the promoter selection is necessary for successful transformation of the exogenous gene. CaMV3 promoter is a frequently used promoter to drive the expression of transgenes in microalgae species such as Chlamydomonas (Kumar et al., 2004), Dunaliella bardwill (Anila et al., 2011), and Parachlorella kessleri (Rathod et al., 2103). In contrast, use of the Ubi promoter for Agrobacterium-mediated transformation in Symbiodinium cells is poorly understood. However, Ubi is a commonly used promotor in transformation studies to generate various transgenic monocot species (Wang et al., 2020; Xu et al., 2017; Koetle et al., 2017). Furthermore, our result demonstrated CaMV35S and UBI promoters could be employed in driving the expression of gene constructs for the functional gene analysis in Symbiodinium.

Insertion of agrobacterium T-DNA was observed in various ways that enabled to obtain the transformation efficiency. We could amplify genomic DNA of transgenic lines created with GUS:35S constructs by PCR method demostrating the successful insertion of T-DNA into the nuclear genomes of Symbiodinium cells. Previous studies described PCR strategies as a powerful tool to identify the mutations in plant cells (Muniz et al., 2014). Moreover, we maintained the transformant Symbiodinium in culture media for protein assesment. Immunoblot analysis showed the presence of expected size of gfp protein was observed. This is similar with previous reports of Agrobacterium mediated transformation with various constructs and reporter genes is driven by ubi promoter (Wang et al., 2020; Xu et al., 2017).

In conclusion, we reported a practical and simple technique Agrobacterium-mediated transformation in Symbiodinium cells. In recent study, fresh endosymbiotic Symbiodinium cells were isolated from Exaiptasia pulchella sample and subjected for $A$. tumifaciens mediated transformation. The plasmids integration was detected by PCR and immunoblot assay. The results showed the efficiency and simple approach that allows an efficient transformation for further understanding of genetic modification in Symbiodinium cells. This method will offer better utilization and exploitation of specifics gene functions and efficient manipulation of Symbiodinium clades.

\section{Ethical Statement}

Not applicable

\section{Funding Information}

This work was supported by a grant from the Ministry of Science and Technology (MOST 109-2637-B150 -001 to PL Jiang)

\section{Author Contribution}

BP carried out the major experimental work, analyzed data, and wrote the paper. PL designated research and wrote the paper.

\section{Conflict of Interest}

The authors declare that they have no conflict of interest. 


\section{References}

Anila, N., Chandrashekar, A., Ravishankar, G.A., \& Sarada, R. (2011). Establishment of Agrobacterium tumefaciensmediated genetic transformation in Dunaliella bardawil. European Journal of Phycology, 46(1), 36-44. https://doi.org/10.1080/09670262.2010.550386

Bundock, P., Dulk-Ras, A., Beijersbergen, A., \& Hooykaas, P.J. (1995). Trans-kingdom T-DNA transfer from Agrobacterium tumefaciens to Saccharomyces cerevisiae. The EMBO Journal, 14 (13), 3206-3214. https://doi.org/10.1002/j.1460-2075.1995.tb07323.x

Cha, T.S., Yee, W., \& Aziz, A. (2012). Assessment of factors affecting Agrobacterium-mediated genetic transformation of the unicellular green alga Chlorella vulgaris. World Journal of Microbiology and Biotechnology, 28(4), 1771-1779. https://doi.org/10.1007/s11274-011-0991-0

Cheng, R., Lin, X., Wang, Z., Yang, S., Rong, H., \& Ma, Y. (2011). Establishment of a transgene expression system for the marine microalga Schizochytrium by $18 \mathrm{~S}$ rDNA-targeted homologous recombination. World Journal of Microbiology and Biotechnology, 7(27), 737-741. https://doi.org/10.1007/s11274-010-0510-8

Davy, S.K., Allemand, D., \& Weis, V.M. (2012). Cell Biology of Cnidarian-Dinoflagellate Symbiosis. Microbiology and Molecular Biology Reviews, 76(2), 229-261. https://doi.org/10.1128/MMBR.05014-11

Gelvin, S.B. (2003). Agrobacterium-mediated plant transformation: the biology behind the 'gene-jockeying tool'. Microbiology and Molecular Biology Reviews, 67(1), 16-37. https://dx.doi.org/10.1128\%2FMMBR.67.1.16-37.2003

Ho, S.L., Tong, W.F., \& Yu, S.M. (2000). Multiple mode regulation of a cysteine proteinase gene expression in rice. Plant Physiology, 122(1), 57-66. https://doi.org/10.1104/pp.122.1.57

Jiang, P.L., Pasaribu, B., \& Chen, C.S. (2014). Nitrogendeprivation elevates lipid levels in Symbiodinium spp. by lipid droplet accumulation: morphological and compositional analyses. PLoS One,9(1), e87416. https://doi.org/10.1371/journal.pone.0087416

Kumara, S.V., Misquitta, R.W., Reddyc, V.S., Raob, B.J., \& Rajama, M.V. (2004). Genetic transformation of the green alga-Chlamydomonas reinhardtii by Agrobacterium tumefaciens. Plant Science, 166(3), 731738. https://doi.org/10.1016/j.plantsci.2003.11.012

Kathiresan, S., Chandrashekar, A., Ravishankar, G.A., \& Sarada, R. (2009). Agrobacterium-mediated transformation in the green alga Haematococcus pluvialis (chlorophyceae. volvocales). Journal of Applied Phycology, 45(3), 642649. https://doi.org/10.1111/j.1529-8817.2009.00688.x

Koetle, M.J., Baskaran, P., Finnie, J.F., Soos, V., Balázs, E., \& van Staden, J. (2017). Optimization of transient GUS expression of Agrobacterium- mediated transformation in Dierama erectum Hilliard using sonication and Agrobacterium. South African Journal of Botany, 111, 307-312. https://doi.org/10.1016/j.sajb.2017.03.025

Liu, X., \& Pijut, P.M. (2010) Agrobacterium-mediated transformation of mature Prunus serotina (black cherry) and regeneration of transgenic shoots. Plant Cell Tissue and Organ Culture, 101(1), 49-57. https://doi.org/10.1007/s11240-009-9662-3

Lohuis, M.R., \& Miller, D.J. (1998). Genetic transformation of dinoflagellates (Amphidinium 632 and Symbiodinium): expression of GUS in microalgae using heterologous promoter 633 constructs. Plant Journal, 13(3), 427-435. https://doi.org/10.1046/j.1365-313X.1998.00040.x

Lorang, J.M., Tuori, R.P., Martinez, J.P., Sawyer, T.L., Redman, R.S., Rollins, J.A., Wolpert, T.J., Johnson, K.B., Rodriguez, R.J., Dickman, M.B., \& Ciuffetti, L.M. (2001). Green fluorescent protein is lighting up fungal biology. Applied and Environmental Microbiology, 67(5), 1987-1994. https://doi.org/10.1128/AEM.67.5.1987-1994.2001

Mahto, B.K., Sharma, P., Rajam, M.V., Reddy, P.M., Ray, S.D. (2018). An efficient method for Agrobacteriummediated genetic transformation of chilli pepper (Capsicum annuum L.). Ind J Plant Physiol. 23(3), 573581. https://doi.org/10.1007/s40502-018-0389-1

Muscatine, L. (1990). The role of symbiotic algae in carbon and energy flux in reef corals. In: Z. Dubinsky, (Eds.), Ecosystems of the World. (pp. 75-87). Coral Reefs. https://doi.org/10.1002/iroh.19930780117

Mayfield, A.B., Chen, M.N., Meng, P.J., Lin, H.J., Chen, C.S., Liu, T.P.J. (2013). The physiological response of the reef coral Pocillopora damicornis to elevated temperature: results from coral reef mesocosm experiments in Southern Taiwan. Marine Environmental Research, 86,111. https://doi.org/10.1016/j.marenvres.2013.01.004

Muñoz, C.F., deJaeger, L., Sturme, M.H., Lip, K.Y., Olijslager, J.W., \& Springer, J. (2018). Improved DNA/protein delivery in microalgae-A simple and reliable method for the prediction of optimal electroporation settings. Algal Research, 33, 448-455. https://doi.org/10.1016/j.algal.2018.06.021

Manickavasagam, M., Subramanyam, K., Ishwarya, R., Elayaraja, D., \& Ganapathi, A. (2015). Assessment of factors influencing the tissue cultureindependent Agrobacterium-mediated in planta genetic transformation of okra Abelmoschus esculentus (L.) Moench. Plant Cell Tissue and Organ Culture, 123(2), 309-320. https://doi.org/10.1007/s11240-015-0836-x

Muñiz, L.M., Gómez, E., Guyon, V., López, M., Khbaya, B., Sellam, O., Peréz, P., \& Hueros, G. (2014). A PCR-based forward genetics screening, using expression domainspecific markers, identifies mutants in endosperm transfer cell development. Frontier in Plant Science, 5, 158. https://doi.org/10.3389/fpls.2014.00158

Newell, C.A. (2000). Plant transformation technology. Developments and applications. Molecular Biotechnology, 16(1), 53-65. https://doi.org/10.1385/MB:16:1:53

Ortiz-Matamoros, M.F., Islas-Flores, T., Voigt, B., Menzel, D., Baluška, F., \& Villanueva, M.A. (2015a). Heterologous DNA uptake in cultured Symbiodinium spp. Aided by Agrobacterium tumefaciens. PLOS ONE, 10(7), e0132693. https://doi.org/10.1371/journal.pone.0132693

Ortiz-Matamoros, M.F., Villanueva, M.A., Islas-Flores, T. (2015b). Transient transformation of cultured photosynthetic dinoflagellates (Symbiodinium spp.) with plant-targeted vectors. Ciencia Marinas, 41(1), 21-32. https://doi.org/10.7773/cm.v41i1.2449

Pasaribu, B., Lin, I.P., Tzen, J.T., Jauh, G.Y., Fan, T.Y., Ju, Y.M., Cheng, J.O., Chen, C.S., \& Jiang, P.L. (2014). SLDP: a novel protein related to caleosin is associated with the endosymbiotic Symbiodinium lipid droplets from Euphyllia glabrescens. Marine Biotechnology, 16(5), 560-571. https://doi.org/10.1007/s10126-014-9574-z

Pasaribu, B., Weng, L.C., Lin, I.P., Camargo, E., Tzen, T.C., Tsai, C.H., Ho, L.S., Lin, M.R., Wang, L.H., Chen, C.S., \& Jiang, 
P.L. (2015). Morphological variability and distinct protein profiles of cultured and endosymbiotic Symbiodinium cells isolated from Exaiptasia pulchella. Scientific Reports, 5, 15353. https://doi.org/10.1038/srep15353

Peng, S.E., Chen, C.S., Song, Y.F., Huang, H.T., Jiang, P.L., Chen, W.N., Fang, L.S., \& Lee, Y.C. (2012). Assessment of metabolic modulation in free-living versus endosymbiotic Symbiodinium using synchrotron radiation-based infrared microspectroscopy. Biology Letters, 8(3), 434-437. https://doi.org/10.1098/rsbl.2011.0893

Rathod, J.P., Prakash, G., Pandit, R., \& Lali, A.M. (2013). Agrobacterium mediated transformation of promising oil-bearing marine algae Parachlorella kessleri. Photosynthesis research, 118(2),141-146. https://doi.org/10.1007/s11120-013-9930-2

Rolfe, S.A., \& Tobin, E.M. (1991). Deletion analysis of a phytochrome-regulated monocot rbcS promoter in a transient assay system. Proceedings of the National Academy of Science United States of America, 88(7), 2683-2686. https://doi.org/10.1073/pnas.88.7.2683

Sharma, A, K., Nymark, M., Sparstad, T., Bones, A.M., \& Winge, P. (2018). Transgene-free genome editing in marine algae by bacterial conjugation - comparison with biolistic CRISPR/Cas9 transformation. Scientific reports, 8, 14401. https://doi.org/10.1038/s41598-018-32342-0

Wang Y-C, Yu M, Shih P-Y, Wu H-Y, \& Lai E-M (2018) Stable pH suppresses defense signaling and is the key to enhance Agrobacterium-mediated transient expression in Arabidopsis seedlings. Scientific reports, 8(1), 17071. https://doi.org/10.1038/s41598-018-34949-9.

Wang, N., Arling, M., Hoerster, G., Ryan, L., Wu, E., Lowe, K., Kamm, G.W., Jones, J.T., Chilcoat, D.N., \& Anand, A. (2020). An Efficient Gene Excision System in Maize. Frontier in Plant Science, 11, 1298.

https://dx.doi.org/10.3389\%2Ffpls.2020.01298

Xu, K., Huang, X., Wu, M., Wang, Y., Chang, Y., Liu, K., Zhang, J., Zhang, Y., Yi, L., Li, T., Wang, R., Tan, G., \& Li, C. (2014). A rapid, highly efficient and economical method of Agrobacterium-mediated in planta transient transformation in living onion epidermis.

PLoS One, 9(1), e83556. https://doi.org/10.1371/journal.pone.0083556

Xu, R., Qin, R., Li, H., Li, D., Li, L., Wei, P., \& Yang, J. (2017). Generation of targeted mutant rice using a CRISPR-Cpf1 system. Plant Biotechnology Journal, 15 (6), 713-717. https://doi.org/10.1111/pbi.12669 